\title{
Suicide risk in depression and bipolar disorder: Do impulsiveness-aggressiveness and pharmacotherapy predict suicidal intent?
}

\author{
Maurizio Pompili ${ }^{1,2}$ \\ Marco Innamorati ${ }^{3}$ \\ Michele Raja ${ }^{4}$ \\ Ilaria Falcone ${ }^{2}$ \\ Giuseppe Ducci ${ }^{5}$ \\ Gloria Angeletti² \\ David Lester ${ }^{6}$ \\ Paolo Girardi² \\ Roberto Tatarelli ${ }^{2}$ \\ Eleonora De Pisa ${ }^{2}$ \\ 'McLean Hospital, Harvard \\ Medical School, Boston, MA, \\ USA; '2Department of Psychiatry, \\ Sant'Andrea Hospital, "Sapienza" \\ University of Rome, Italy; ${ }^{3}$ Università \\ Europea di Roma, Italy; ${ }^{4}$ Diagnostic \\ and Therapeutic Psychiatric Services, \\ Department of Mental Health, \\ Santo Spirito Hospital, Rome, \\ Italy; ${ }^{5}$ Diagnostic and Therapeutic \\ Psychiatric Services, Department \\ of Mental Health, San Filippo Neri \\ Hospital, Rome, Italy; ${ }^{6}$ Center for the \\ Study of Suicide, Blackwood, NJ, USA
}

Correspondence: Maurizio Pompil Sant'Andrea Hospital, Dept. of Psychiatry, Via di Grottarossa 1035, 0189 Roma, Italy Email maurizio.pompili@uniromal.it or mpompili@mclean.harvard.edu

\begin{abstract}
The aims of the present study were to examine clinical, personality, and sociodemographic predictors of suicide risk in a sample of inpatients affected by major affective disorders. The participants were 74 inpatients affected by major depressive disorder or bipolar disorder-I. Patients completed a semi-structured interview, the Beck Hopelessness Scale, the Aggression Questionnaire, the Barratt Impulsiveness Scale, and the Hamilton scales for depression and anxiety. Over $52 \%$ of the patients were high suicide risks. Those at risk reported more severe depressive-anxious symptomatology, more impulsivity and more hostility. Impulsivity, the use of antidepressants, anxiety/somatization, and the use of mood stabilizers (a negative predictor) resulted in accurate predicting of suicide intent. Impulsivity and antidepressant use were the strongest predictors even after controlling for several sociodemographic and clinical variables.
\end{abstract}

Keywords: suicide, mood disorders, pharmacotherapy, impulsiveness, aggressiveness

\section{Introduction}

Suicide is a major worldwide public health problem. Nearly one million lives are lost each year to suicide, and between $3 \%-5 \%$ of adults make at least one suicide attempt at some point in their life (Kessler et al 1999; Weissman et al 1999; Szadoczky et al 2000).

The relationship between suicide and psychiatric disorders is an important issue. More than two-thirds of suicide completers and suicide attempters have (mostly untreated) major depressive episodes at the time of the suicidal act (Coryell and Young 2005). People with major affective disorders (MAD), that is, unipolar major depressive disorder (MDD) and bipolar disorder type I and type II (BPD-I, BPD-II) are highly vulnerable to suicidal behavior. It is estimated that individuals with BPD are 30 times more likely to attempt suicide than those with no psychiatric disorder (Chen and Dilsaver 1996; Kessler et al 1999; Potash et al 2000). Suicide behavior in major affective disorders is also characterized by high lethality (Baldessarini et al 2006c), as indicated by the ratio of estimated rates of attempted suicide to completed suicide. Between $6 \%-20 \%$ of bipolar patients die by suicide compared with 25\%-56\% attempting suicide (Goodwin and Jamison 1990; Harris and Barraclough 1997; Inskip et al 1998).

However, as Hendin (1986) pointed out, "the vast majority of depressed, schizophrenic, alcoholic or organically psychotic patients do not commit or even attempt suicide". Hendin went on to suggest that "the interest in classifying populations of suicidal patients by their psychiatric diagnoses is being supplemented by an interest in understanding what makes a minority of patients within any given diagnostic category suicidal while the majority are not suicidal".

The search for suicide risk factors, variables which indicate an increased likelihood for suicide, independent of diagnosis, has been espoused by a number of researchers and 
clinicians. Most studies have evaluated short-term risk factors for suicidal behavior, such as suicidal ideation and recent suicide attempt, the major precursors and the most powerful predictors of attempted and completed suicide (Coryell and Young 2005; Hawton et al 2005; Rihmer 2007).

However, a single risk factor is not sufficient to predict suicide (Bongar 2000). Despite intensive efforts, effective prediction and prevention strategies have remained elusive, suggesting that our understanding of the interplay of factors that increase the risk of suicide remains incomplete. Prediction of suicidal behavior in the long-term and lists of personality predictors are also important and challenging tasks for the clinician (Stelmachers 1995).

Impulsivity/aggression has been reported to be related to suicidal behavior in several studies (Weissman et al 1973; Dumais et al 2005; Galfalvy et al 2006). For example, Mann and colleagues (1999) proposed a stress-diathesis model of suicidal behavior. Impulsivity, related to genetic predisposition and dysfunctions of the prefrontal cortex, is part of the diathesis predisposing individuals with suicidal ideation to act upon their impulse. Higher aggression may also contribute to the increased lethality of suicide attempts (Baca-Garcia et al 2006).

In 2004, the United States Food and Drug Administration (FDA) warned of suicidality in children and adolescents after antidepressant treatment (FDA 2004). However, several studies have failed to produce evidence of a significant effect of antidepressants on suicide risk (Simon et al 2006; Sondergard et al 2006). For example, Tiihonen and colleagues (2006), in a national cohort study of suicidal subjects who had used antidepressants, found that the current use of any antidepressant was associated with a markedly increased risk of attempting suicide and, at the same time, with a markedly decreased risk of completed suicide. According to this study, the lower overall mortality was attributable to a decrease in cardiovascular and cerebrovascular-related deaths during selective serotonin reuptake inhibitor use.

The literature supports the efficacy of long-term lithium treatment for suicidal patients (Thies Flechtner et al 1996; Baldessarini et al 2003, 2006b, 2006d), and lithium is considered to be the first-line treatment for reducing the risk of suicide (Grunze et al 2002) while there is weaker evidence for the usefulness of anticonvulsivants in preventing suicide (Thies Flechtner et al 1996; Goodwin et al 2003). There is also evidence that atypical antipsychotics, particularly clozapine, may contribute to a reduction in suicidality in patients with affective disorders (Anonymous 1998).
Thus, impulsive/aggression may be a powerful risk factor for suicidal behavior. It may play a role as a diathesis predisposing individuals with acute disorders (stressors) to act upon their suicidal ideation. Pharmacotherapy may play a strong role in reducing suicidal intent, via different mechanisms, for example, either reducing impulsivity, suicide ideation, or hopelessness.

The aims of the present study were to examine the single role of impulsivity/aggression on increasing suicidal intent, and the role of several pharmacological agents in reducing suicidal intent in a sample of MAD inpatients. The next step was to examine the multivariate relationship between impulsivity/aggression, pharmacotherapy and hopelessness, controlling for potential confounders.

Although, some authors assessed impulsivity/aggression via lifetime aggressive behavior, we preferred to assess stable personality-like traits and both covert and overt components. Impulsivity is essentially related to the control of thoughts and behavior, and to the ability to observe and conform to social norms in society. Trait aggression focuses on the intent, the means of expression, and the affective factors that influence aggression. Thus, trait aggression is both a feeling of hostility that arouses thoughts of attacking others, the disposition to act out one's hostility, and violent or deliberately unfriendly behavior.

Suicidal intent was measured via hopelessness. Hopelessness is a cognitive trait associated with suicide, leading suicidal patients to believe that suicide is the only feasible strategy for dealing with their seemingly insoluble problems. The relationship between hopelessness and suicidal intent has been supported by empirical research (Bedrosian and Beck 1979; Wetzel et al 1980; Chandrasekaran and Gnanaselane 2005). Beck and colleagues (1985, 1990) carried out two prospective study of inpatient and outpatient samples. The authors found that hopelessness scores were related significantly to eventual completed suicide. A cutoff score of 9 or above identified most of the patients who eventually committed suicide. The high-risk group identified in the latter study was 11 times more likely to commit suicide than the rest of the outpatients. Thus, hopelessness may be used as an indicator of suicide potential (Table 1).

\section{Methods and materials \\ Participants}

Participants were 74 inpatients (37 men, 37 women) consecutively admitted to three psychiatric acute wards located in Rome. The patients admitted showed either 
Table I Risk factors for suicide in bipolar disorder (adapted from Baldessarini et al 2006a)

Early in the course of illness

Younger age

Depressive, mixed dysphoric-irritable states

Caucasian ethnicity

Being unmarried

Previous depression

Previous dysphoric-agitated states

Hopelessness

Previous suicide attempts

Substance or alcohol abuse

Impulsivity

Stressful life events (deaths, divorce, separations, scandals, etc)

Suicidal ideation

Limited access to support or clinical services

psychotic-like symptoms, suicidal behavior, or aggressive behavior. Inclusive criteria were diagnosis of a DSM-IV-TR major affective disorder (unipolar major depressive disorder or bipolar disorder type I, currently experiencing a depressive episode). Exclusion criteria were diagnosis of mood disorders not listed above (eg, cyclothymia, bipolar disorder type II, etc), diagnosis of dementia or delirium, current or past history of schizophrenia and schizoaffective disorder, illiteracy or any condition that made the subject unable to complete the assessment or give informed consent. The average ages for participants were: women 44.32 years $(\mathrm{SD}=13.01)$ and men 39.76 years $(\mathrm{SD}=12.39)$. At intake, the patients were assessed for psychiatric diagnoses and the scales were administered. A consultant psychiatrist assessed MAD diagnosis by structured interview, evaluating the differential diagnosis using DSM-IV diagnostic algorithms and clinical judgement. The clinical and demographic characteristics of the patients are listed in Table 2. Twenty-eight patients were diagnosed with unipolar MDD and 46 patients were diagnosed with BPD-I.

Subjects participated voluntarily in the study, and each subject provided written informed consent. The study protocol received ethics approval from the local research ethics review board. Patients were interviewed on average five days after intake

\section{Instruments}

Patients completed the Mini International Neuropsychiatric Interview (MINI) Italian Version 5.0.0 (Sheehan et al 1998), the Beck Hopelessness Scale (BHS), the Aggression Questionnaire (AQ) (Buss and Perry 1992), the Barratt Impulsiveness Scale (BIS-11) (Patton et al 1995), the
Hamilton Rating Scale for Depression (HAM-D) (Hamilton 1960, 1967) and the Hamilton scale for Anxiety (HAM-A) (Hamilton 1959).

The BHS is a 20-item scale for measuring the cognitive component of the syndrome of depression. This scale assesses three major aspects of hopelessness: feelings about the future, loss of motivation, and expectations.

The AQ contains 29 self-report Likert-type items (eg, "I tell my friends openly when I disagree with them", "Given enough provocation, I may hit another person") assessing cognitive, affective, and behavioral components of this domain. Subscales include Hostility (ie, hostile cognition), Anger (ie, hostile affect), Physical Aggression, and Verbal Aggression.

The BIS-11 is a 30-item questionnaire (eg, "I act on impulse", "I plan tasks carefully") that has been validated in several different populations. The BIS-11 includes three subscales labeled attentional, nonplanning, and motor (Patton et al 1995). These three subscales have been replicated in an Italian population (Fossati et al 2001). However, subfactor item loadings differed between the English and Italian versions: the first factor (F1) combined attention and motor impulsiveness, the second factor (F2) was defined by perseverance and lack of delay in obtaining gratification, while the third Factor (F3) reproduced the original factor nonplanning impulsiveness.

\section{Results}

Patients reported high scores on hopelessness, and over $52 \%$ evidenced scores higher than 9, indicating high suicide intent (see Table 2). No differences were found by sex or diagnosis (see Tables 2 and 3). Twenty-seven people (36.5\%) reported a history of suicide attempts, and $16(21.6 \%)$ reported multiple suicide attempts. Female patients were more likely to have attempted suicide than male patients, while men reported more physical aggressiveness. No differences were revealed between MDD and BPD patients. Thus, we may consider inpatients with MAD to be a group at high risk of suicide behavior, with the female patients at higher risk.

The analysis indicated differences between patients with the two diagnoses (see Table 3). Patients with major depressive disorder reported more depression, somatization and symptoms of anxiety, retardation and diurnal variation.

When considering the differences between the group with high risk of suicide and the group with low risk, as measured by the BHS, several differences were identified. The patients at risk reported more severe depressive and anxious symptomatology, and more impulsivity 
Table 2 Socio-demographic and clinical variables broken down by sex

\begin{tabular}{|c|c|c|c|c|c|}
\hline Variables & $\begin{array}{l}\text { Total } \\
(N=74)\end{array}$ & $\begin{array}{l}\text { Men } \\
(N=37)\end{array}$ & $\begin{array}{l}\text { Women } \\
(N=37)\end{array}$ & $\begin{array}{l}\text { Test } \\
\text { (Sig.) }\end{array}$ & $\begin{array}{l}\text { Effect } \\
\text { sizes }\end{array}$ \\
\hline Age - M (SD) & $42.04(12.83)$ & $39.76(12.39)$ & $44.32(13.01)$ & $1.55^{\mathrm{a}}(0.13)$ & \\
\hline MDD - N (\%) & $28(37.8)$ & $12(32.4)$ & $16(43.2)$ & $0.24^{\mathrm{b}}$ & \\
\hline $\mathrm{BPD}-\mathrm{N}(\%)$ & $46(62.2)$ & $25(67.6)$ & $21(56.8)$ & & \\
\hline Suicide attempts - N (\%) & $27(36.5)$ & $9(24.3)$ & $18(48.6)$ & $0.03^{\mathrm{b}}$ & $\Phi=-0.25$ \\
\hline $\begin{array}{l}\text { Multiple suicide } \\
\text { attempts - N (\%) }\end{array}$ & $16(21.6)$ & $6(16.2)$ & $10(27.0)$ & $0.20^{\mathrm{b}}$ & \\
\hline $\mathrm{BIS}-\mathrm{M}(\mathrm{SD})$ & $67.68(13.92)$ & $67.16(12.03)$ & $68.19(15.74)$ & $0.32^{\mathrm{a}}(0.75)$ & \\
\hline $\mathrm{FI}-\mathrm{M}(\mathrm{SD})$ & $21.81(6.60)$ & $21.86(5.95)$ & $21.76(7.26)$ & $-0.07^{a}(0.94)$ & \\
\hline$F 2-M(S D)$ & $25.61(5.62)$ & $25.68(4.87)$ & $25.54(6.34)$ & $-0.10^{\mathrm{a}}(0.92)$ & \\
\hline$F 3-M(S D)$ & $20.26(5.18)$ & $19.62(5.13)$ & $20.89(5.23)$ & $1.055^{\mathrm{a}}(0.30)$ & \\
\hline$A Q-M(S D)$ & $72.35(17.45)$ & $74.78(17.82)$ & $69.92(16.97)$ & $-1.20^{\mathrm{a}}(0.23)$ & \\
\hline$P A-M(S D)$ & $18.50(7.67)$ & $21.11(8.71)$ & $15.89(5.44)$ & $-3.09^{a}(0.003)$ & $\mathrm{D}=0.72$ \\
\hline$V A-M(S D)$ & $13.86(4.14)$ & $13.76(4.22)$ & I $3.97(4.11)$ & $0.22^{\mathrm{a}}(0.82)$ & \\
\hline$A-M(S D)$ & $17.35(5.66)$ & $17.32(5.46)$ & $17.38(5.92)$ & $0.04^{a}(0.97)$ & \\
\hline$H-M(S D)$ & $22.64(6.59)$ & $22.59(6.95)$ & $22.68(6.30)$ & $0.05^{\mathrm{a}}(0.96)$ & \\
\hline $\mathrm{BHS}-\mathrm{M}(\mathrm{SD})$ & $9.53(5.34)$ & $9.70(5.45)$ & $9.35(5.29)$ & $-0.28^{\mathrm{a}}(0.78)$ & \\
\hline $\mathrm{BHS} \geq 9-\mathrm{N}(\%)$ & $39(52.7)$ & $20(54.1)$ & $19(51.4)$ & $0.50^{\mathrm{b}}$ & \\
\hline $\begin{array}{l}\text { Feelings about the } \\
\text { future }-M(S D)\end{array}$ & $1.81(1.63)$ & $1.81(1.65)$ & $1.81(1.63)$ & $0.00^{\mathrm{a}}(1.00)$ & \\
\hline $\begin{array}{l}\text { Loss of motivation }-M \\
\text { (SD) }\end{array}$ & $3.62(2.30)$ & $3.68(2.38)$ & $3.57(2.26)$ & $-0.20^{\mathrm{a}}(0.84)$ & \\
\hline $\begin{array}{l}\text { Expectations - M } \\
\text { (SD) }\end{array}$ & $3.28(1.57)$ & $3.4 \mathrm{I}(1.59)$ & $3.16(1.56)$ & $-0.67^{\mathrm{a}}(0.5 \mathrm{I})$ & \\
\hline HAM-A - M (SD) & $19.03(8.06)$ & $20.05(8.66)$ & $18.00(7.40)$ & $-1.0 \mathrm{I}^{\mathrm{a}}(0.28)$ & \\
\hline $\begin{array}{l}\text { Somatic anxiety }-M \\
\text { (SD) }\end{array}$ & $6.84(4.87)$ & $7.70(5.42)$ & $5.97(4.14)$ & $-1.54^{\mathrm{a}}(0.13)$ & \\
\hline $\begin{array}{l}\text { Psychic anxiety - M } \\
\text { (SD) }\end{array}$ & $12.19(4.81)$ & $12.35(4.84)$ & $12.03(4.85)$ & $-0.29^{a}(0.77)$ & \\
\hline HAM-D - M (SD) & $20.59(7.29)$ & $21.19(6.70)$ & $20.00(7.88)$ & $-0.70^{\mathrm{a}}(0.49)$ & \\
\hline $\begin{array}{l}\text { Anxiety/somatization - M } \\
\text { (SD) }\end{array}$ & $6.73(3.35)$ & $6.62(3.23)$ & $6.84(3.5 \mathrm{I})$ & $0.28^{a}(0.78)$ & \\
\hline $\begin{array}{l}\text { Weight loss - M } \\
\text { (SD) }\end{array}$ & $0.77(1.15)$ & $0.84(1.17)$ & $0.70(1.15)$ & $-0.50^{\mathrm{a}}(0.62)$ & \\
\hline $\begin{array}{l}\text { Cognitive disturbance - } \\
M \text { (SD) }\end{array}$ & $5.80(2.95)$ & $5.5 \mathrm{I}(3.0 \mathrm{I})$ & $6.08(2.91)$ & $0.83^{\mathrm{a}}(0.4 \mathrm{I})$ & \\
\hline $\begin{array}{l}\text { Diurnal variation - } \\
M(S D)\end{array}$ & $1.00(1.40)$ & $\mathrm{I} .14$ (I.48) & $0.86(1.34)$ & $-0.83^{\mathrm{a}}(0.4 \mathrm{I})$ & \\
\hline $\begin{array}{l}\text { Retardation - M } \\
\text { (SD) }\end{array}$ & $6.24(3.36)$ & $7.08(2.85)$ & $5.4 \mathrm{I}(3.66)$ & $-2.20^{\mathrm{a}}(0.03)$ & $D=0.5 I$ \\
\hline $\begin{array}{l}\text { Sleep disturbance - M } \\
\text { (SD) }\end{array}$ & $2.54(\mathrm{I} .4 \mathrm{I})$ & $2.76(1.517)$ & $2.32(1.27)$ & $-1.33^{\mathrm{a}}(0.19)$ & \\
\hline
\end{tabular}

Notes: ${ }^{a}$ - t-test; ${ }^{\text {b }}-$ I-FET.

Abbreviations: MDD, major depressive disorder; BPD, bipolar disorder; BIS, Barratt Impulsiveness Scale; AQ, Aggression Questionnaire; PA, Physical Aggression; VA, Verbal Aggression; A, Anger; H, Hostility; BHS, Beck Hopelessness Scale; HAM-D, Hamilton scale for Depression; HAM-A, Hamilton scale for Anxiety; I-FET, one-way Fisher exact test; M, mean; SD, standard deviation; D, Cohen's D index; $\Phi$, Phi coefficient.

and hostility. Thus, MAD patients at risk of suicide experience an increasing burden of depressive and anxiety symptoms and hostility in their relationships and act more impulsively.

The differences reported were reflected in the therapy. More antidepressants (sertraline $50 \mathrm{mg}$ /daily, paroxetine $20 \mathrm{mg} /$ daily, fluoxetine $20 \mathrm{mg}$ /daily) had been prescribed to patients at risk for suicide, but fewer mood stabilizers (average doses: lithium $900 \mathrm{mg}$ /daily, lamotrigine $200 \mathrm{mg} /$ daily, carbamazepine $1300 \mathrm{mg}$ /daily) and antipsychotics (olanzapine $20 \mathrm{mg}$ /daily, quetiapine $700 \mathrm{mg} /$ daily). There was a slight tendency for the high-risk patients to report more cognitive disturbances.

To identify the best predictors of the BHS total score, sociodemographic and clinical variables were entered as predictors in a multiple regression model (see Table 4). In the first step, the best predictor was only the BIS, and the model explained $31 \%$ of the variability of the BHS scores. The second step added the use of antidepressants as a predictor, with the model explaining another $13 \%$ 
Table 3 Sociodemographic and clinical variables broken down by diagnosis and suicide risk

\begin{tabular}{|c|c|c|c|c|c|c|c|c|}
\hline Variables & MDD & BPD & Test (Sig.) & $\begin{array}{l}\text { Effect } \\
\text { sizes }\end{array}$ & \begin{tabular}{|l|}
$\begin{array}{l}\text { No risk of } \\
\text { suicide }\end{array}$ \\
\end{tabular} & $\begin{array}{l}\text { High risk of } \\
\text { suicide }\end{array}$ & Test (Sig.) & $\begin{array}{l}\text { Effect } \\
\text { sizes }\end{array}$ \\
\hline Age - M (SD) & $45.86(15.25)$ & $39.72(10.62)$ & $1.87^{\mathrm{a}}(0.07)$ & & $37.23(10.14)$ & $46.36(13.55)$ & $-3.25^{\mathrm{a}}(0.002)$ & $D=-0.76$ \\
\hline $\mathrm{BHS}-\mathrm{M}(\mathrm{SD})$ & $10.43(4.93)$ & $8.98(5.55)$ & $1.14^{\mathrm{a}}(0.26)$ & & - & - & - & \\
\hline $\mathrm{BHS} \geq 9-\mathrm{N}(\%)$ & $18(46.2)$ & $21(53.8)$ & $0.09^{b}$ & & - & - & - & \\
\hline Feelings about the future $-M(S D)$ & $2.11(1.64)$ & $1.63(1.61)$ & $1.23^{\mathrm{a}}(0.22)$ & & - & - & - & \\
\hline Loss of motivation - M (SD) & $3.79(2.33)$ & $3.52(2.31)$ & $0.48^{\mathrm{a}}(0.64)$ & & - & - & - & \\
\hline Expectations - M (SD) & $3.54(1.35)$ & $3.13(1.68)$ & $1.08^{\mathrm{a}}(0.28)$ & & - & - & - & \\
\hline HAM-A - M (SD) & $20.96(9.15)$ & $17.85(7.18)$ & $1.63^{\mathrm{a}}(0.1 \mathrm{I})$ & & $16.31(7.92)$ & $21.46(7.48)$ & $-2.88^{\mathrm{a}}(0.0 \mathrm{I})$ & $D=-0.67$ \\
\hline Somatic anxiety - M (SD) & $6.89(5.5 \mathrm{I})$ & $6.80(4.49)$ & $0.08^{\mathrm{a}}(0.94)$ & & $6.14(4.70)$ & $7.46(4.99)$ & $-1.17^{\mathrm{a}}(0.25)$ & \\
\hline Psychic anxiety - M (SD) & | $4.07(4.9 \mid)$ & II.04 (4.42) & $2.74^{\mathrm{a}}(0.0 \mathrm{I})$ & $D=0.65$ & $10.17(4.36)$ & $14.00(4.5 I)$ & $-3.70^{\mathrm{a}}(0.000)$ & $D=-0.86$ \\
\hline HAM-D - M (SD) & $23.57(7.14)$ & I8.78 (6.84) & $2.87^{\mathrm{a}}(0.0 \mathrm{I})$ & $D=0.69$ & 16.7I (7.06) & $24.08(5.58)$ & $-5.00^{\mathrm{a}}(0.000)$ & $D=-1.16$ \\
\hline Anxiety/somatization - M (SD) & $7.89(3.34)$ & $6.02(3.19)$ & $2.4 I^{\mathrm{a}}(0.02)$ & $D=0.57$ & $4.89(2.92)$ & $8.38(2.83)$ & $-5.24^{a}(0.000)$ & $D=-1.22$ \\
\hline Weight loss - M (SD) & $0.68(1.19)$ & $0.83(1.14)$ & $-0.53^{\mathrm{a}}(0.60)$ & & $0.60(1.04)$ & $0.92(1.24)$ & $-\left.1.2\right|^{a}(0.23)$ & \\
\hline Cognitive disturbance $-M(S D)$ & $6.14(2.65)$ & $5.59(3.13)$ & $0.78^{\mathrm{a}}(0.44)$ & & $5.40(3.10)$ & $6.15(2.8 I)$ & $-1.10^{\mathrm{a}}(0.28)$ & \\
\hline Diurnal variation - M (SD) & $1.46(1.50)$ & $0.72(1.28)$ & $2.19^{\mathrm{a}}(0.03)$ & $D=0.54$ & $1.06(1.47)$ & $0.95(1.36)$ & $0.33^{\mathrm{a}}(0.74)$ & \\
\hline Retardation - M (SD) & $7.93(2.93)$ & $5.22(3.22)$ & $3.63^{\mathrm{a}}(0.00 \mathrm{I})$ & $D=0.88$ & $4.63(3.30)$ & $7.69(2.73)$ & $-4.37^{\mathrm{a}}(0.000)$ & $D=-|.0|$ \\
\hline Sleep disturbance - M (SD) & $2.46(1.29)$ & $2.59(1.48)$ & $-0.36^{\mathrm{a}}(0.72)$ & & $2.49(1.48)$ & $2.59(1.35)$ & $-0.32^{\mathrm{a}}(0.75)$ & \\
\hline BIS - M (SD) & 68.71 (12.57) & $67.04(14.78)$ & $0.50^{\mathrm{a}}(0.62)$ & & $60.54(10.60)$ & $74.08(13.52)$ & $-4.75^{\mathrm{a}}(0.000)$ & $D=-I . I I$ \\
\hline $\mathrm{FI}-\mathrm{M}(\mathrm{SD})$ & $22.21(6.70)$ & $21.57(6.60)$ & $0.4 I^{\mathrm{a}}(0.68)$ & & $18.5 \mid(4.91)$ & $24.77(6.56)$ & $-4.60^{\mathrm{a}}(0.000)$ & $D=-1.08$ \\
\hline $\mathrm{F} 2-\mathrm{M}(\mathrm{SD})$ & $25.29(5.17)$ & $25.80(5.92)$ & $-0.38^{\mathrm{a}}(0.70)$ & & 24.11 (4.79) & $26.95(6.01)$ & $-2.23^{\mathrm{a}}(0.03)$ & $D=-0.52$ \\
\hline F3 - M (SD) & $21.21(4.99)$ & $19.67(5.27)$ & $1.24^{\mathrm{a}}(0.22)$ & & | 17.91 (4.96) & $22.36(4.48)$ & $-4.05^{\mathrm{a}}(0.000)$ & $D=-0.94$ \\
\hline$A Q-M(S D)$ & $71.07(\mid 8.8 I)$ & $73.13(16.74)$ & $-0.49^{\mathrm{a}}(0.63)$ & & $70.40(18.57)$ & $74.10(16.43)$ & $-0.9 \mathrm{I}^{\mathrm{a}}(0.37)$ & \\
\hline $\mathrm{PA}-\mathrm{M}(\mathrm{SD})$ & $17.89(7.56)$ & I8.87 (7.80) & $-0.53^{\mathrm{a}}(0.60)$ & & $19.09(8.50)$ & $17.97(6.92)$ & $0.62^{\mathrm{a}}(0.54)$ & \\
\hline VA - M (SD) & I3.93 (4.36) & I3.83 (4.05) & $0.10^{\mathrm{a}}(0.92)$ & & I4.23 (4.02) & I3.54 (4.27) & $0.7 \mathrm{I}^{\mathrm{a}}(0.48)$ & \\
\hline$A-M(S D)$ & $17.07(5.45)$ & $17.52(5.83)$ & $-0.33^{\mathrm{a}}(0.74)$ & & I $6.77(5.94)$ & $17.87(5.42)$ & $-0.83^{\mathrm{a}}(0.4 \mathrm{I})$ & \\
\hline$H-M(S D)$ & $22.18(6.66)$ & $22.91(6.61)$ & $-0.46^{\mathrm{a}}(0.65)$ & & $20.31(6.07)$ & $24.72(6.4 I)$ & $-3.03^{\mathrm{a}}(0.003)$ & $D=-0.71$ \\
\hline Suicide attempts - N (\%) & $10(35.7)$ & $17(37.0)$ & $0.56^{\mathrm{b}}$ & & II (3I.4) & $16(41.0)$ & $0.27^{b}$ & \\
\hline Multiple suicide attempts - N (\%) & $6(21.4)$ & $10(21.7)$ & $0.6 \mathrm{I}^{\mathrm{b}}$ & & $8(22.9)$ & $8(20.5)$ & $0.5 \mathrm{I}^{\mathrm{a}}$ & \\
\hline Mood stabilizer - N (\%) & $22(78.6)$ & $4 \mid(89.1)$ & $0.18^{\mathrm{b}}$ & & $33(94.3)$ & $30(76.9)$ & $0.04^{b}$ & $\Phi=-0.24$ \\
\hline Antidepressants - N (\%) & $12(57.1)$ & $3(6.5)$ & $0.000^{\mathrm{b}}$ & $\Phi=-0.44$ & $3(8.6)$ & $12(30.8)$ & $0.02^{\mathrm{b}}$ & $\Phi=0.28$ \\
\hline Antipsychotics - N (\%) & $20(7 \mid .4)$ & $43(93.5)$ & $0.0 \mathrm{I}^{\mathrm{b}}$ & $\Phi=0.30$ & $34(97.1)$ & $29(74.4)$ & $0.006^{\mathrm{b}}$ & $\Phi=-0.32$ \\
\hline Anxiolytics - N (\%) & II (39.3) & $10(21.7)$ & $0.09^{\mathrm{b}}$ & & $8(22.9)$ & $13(33.3)$ & $0.23^{b}$ & \\
\hline
\end{tabular}

Notes: ${ }^{\mathrm{a}}$-test; ${ }^{\mathrm{b}} \mathrm{I}-\mathrm{FET}$.

Abbreviations: MDD, major depressive disorder; BPD, bipolar disorder; BIS, Barratt Impulsiveness Scale; AQ, Aggression Questionnaire; PA, Physical Aggression;VA, Verbal Aggression; A, Anger; H, Hostility; BHS, Beck Hopelessness Scale; HAM-D, Hamilton scale for Depression; HAM-A, Hamilton scale for Anxiety; I-FET, one-way Fisher exact test; M, mean; SD, standard deviation; D, Cohen's D index; $\Phi$, Phi coefficient.

of the BHS variability. The third step added anxiety/ somatization as predictor (with an additional $6 \%$ of the variability explained). The last step added the use of mood stabilizers as negative predictor, that is, as a protective factor. The four predictors explained $50 \%$ of the variance in BHS scores.

To verify if pharmacotherapy and impulsiveness/ aggression were strong predictors even after controlling for diagnosis, depression and anxiety, and demographic variables, we performed a hierarchical multiple regression analysis (not reported in a table). In the first block, we introduced the variables to be controlled and in the second block we introduced the BIS, the AQ, and the pharmacotherapy variables. This resulted in a significant model explaining nearly $47 \%$ of the variance of BHS scores $\left(\mathrm{F}(13.60)=5.97 ; \mathrm{p}=0.00 ; \mathrm{R}^{2}\right.$ change $=0.37 ; \mathrm{F}$ change $(6.60)=7.70 ; \mathrm{p}=0.00)$. The BIS scores (Beta std. $=0.58$; $\mathrm{t}=5.66 ; \mathrm{p}=0.00)$ and antidepressant use (Beta std. = $0.34 ; \mathrm{t}=2.96 ; \mathrm{p}=0.004)$ were confirmed to be strong predictors.

\section{Discussion}

Our results are consistent with the view that people with MAD are highly vulnerable to suicidal behavior, and the women were the group were more likely to have attempted suicide than were the men. This is also consistent with the study by Schneider and colleagues (2001) who, analyzing mortality data from a prospective study of 354 outpatients 
Table 4 Multiple regression (Stepwise)

\begin{tabular}{|c|c|c|c|c|c|c|}
\hline \multirow[b]{2}{*}{ Step } & \multirow[b]{2}{*}{ Predictors } & \multicolumn{4}{|c|}{ Criterion: BHS } & \\
\hline & & Beta Std. & $\mathbf{t}$ & Sig. & Multicollinearity tolerance & \\
\hline I & BIS & 0.56 & 5.76 & 0.00 & 1.00 & \\
\hline \multirow[t]{2}{*}{2} & BIS & 0.60 & 6.79 & 0.00 & 0.99 & \\
\hline & Antidepressants & 0.36 & 4.08 & 0.00 & 0.99 & \\
\hline \multirow[t]{3}{*}{3} & BIS & 0.53 & 5.88 & 0.00 & 0.89 & \\
\hline & Antidepressants & 0.30 & 3.48 & 0.001 & 0.93 & \\
\hline & Anxiety/somatization & 0.26 & 2.86 & 0.01 & 0.87 & \\
\hline \multirow[t]{4}{*}{4} & BIS & 0.51 & 5.75 & 0.00 & 0.88 & \\
\hline & Antidepressants & 0.23 & 2.54 & 0.01 & 0.80 & \\
\hline & Anxiety/somatization & 0.28 & 3.12 & 0.003 & 0.86 & \\
\hline & Mood stabiliser & -0.18 & -2.03 & 0.05 & 0.86 & \\
\hline Model & Adjusted $\mathbf{R}^{2}$ & $\mathbf{F}$ & Sig. & $\mathbf{R}^{2}$ change & F change & Sig. F change \\
\hline 1 & 0.31 & 33.16 & 0.00 & 0.32 & 33.16 & 0.00 \\
\hline 2 & 0.43 & 28.50 & 0.00 & 0.13 & 16.64 & 0.00 \\
\hline 3 & 0.48 & 23.64 & 0.00 & 0.06 & 8.16 & 0.01 \\
\hline 4 & 0.50 & 19.54 & 0.00 & 0.03 & 4.10 & 0.05 \\
\hline
\end{tabular}

Abbreviations: BHS, Beck Hopelessness Scale; BIS, Barratt Impulsiveness Scale.

with affective disorders during a follow-up period of 5 years, observed nearly three times (SMR 2.9) the number of deaths expected on the basis of age- and sex-standardized reference population rates. Death from unnatural causes was 28.8 times higher than expected. Women with affective disorders had a very high risk of dying from unnatural causes (SMR 47.1). It seems that dysregulation of emotion follows different patterns of externalization/internalization in women and men with MAD. In stress-provoking situations, women are more likely to attempt suicide, while men report more external physical aggressiveness. Given the high risk of completed suicide in those patients suffering from major affective disorders and judged to be at high risk of suicide, it is crucial to perform a comprehensive assessment of suicide. Lester (1993) performed a meta-analysis of studies of suicidal behavior in patients with bipolar and unipolar affective disorders and found two possible trends: an excess of subsequent completed suicide in unipolar patients and an excess of subsequent attempted suicide in bipolar patients.

Our results indicated that impulsivity may be a strong predictor for suicide intent. MAD patients with problems of impulse control are at higher risk for suicide. Impulsivity was able to predict suicide even when controlling for diagnosis, anxiety and depression severity, and sociodemographic variables. Those variables were identified as important risk factors for suicide by the US Surgeon General in the 1999 document entitled "Call to action to prevent suicide", a milestone for the dissemination of warnings to mental health professionals and general population alike (US Public Health
Service 1999). Moreover, Dumais and colleagues (2005) found that impulsive-aggressive personality disorders and alcohol abuse/dependence were two independent predictors of suicide in major depression, and impulsive and aggressive behaviors seem to underlie these risk factors.

The analysis indicated differences in the drug therapy between patients at risk of suicide and patients without risk. Patients reporting more hopelessness are more likely to have been prescribed antidepressants (SSRI) and less likely to have been prescribed mood stabilizers (lithium, carbamazepine, lamotrigine) and antipsychotics (olanzapine, quetiapine), the effect sizes of this difference being low/moderate. This might be due to the strong relationship between depression and hopelessness; however, suicide risk may be understood as constriction, tunneling, or focusing or narrowing the range of options usually available to an individual's consciousness, when the individual cannot see any way out and therefore loses any positive expectation about the future, which leads to a hopeless feeling regardless of diagnosis. The fact that those experiencing hopelessness were prescribed more antidepressants should be viewed with caution. In fact, evidence emerging from clinical practice is suggestive that mood stabilizers can decrease the feelings of anguish and despair that are often associated with hopelessness both in unipolar and bipolar patients. Moreover, such drugs reduce the agitation components of depressive-dysphoric states which often are correlated with impulsiveness and aggression and often found in suicidal crisis. 
Baldessarini and colleagues (2006d) suggested that the antisuicidal properties of lithium in bipolar disorder may act upon these components. Moreover, lithium has proven to be the best antisuicidal treatment even in major depression (Guzzetta et al 2007). However, we had no access to medical records regarding past pharmacotherapy in our patients, and we cannot know if any causal relationship exists between the variables. This could be important because there is growing evidence for suicidal risk reduction with long-term lithium maintenance (Thies Flechtner et al 1996; Baldessarini et al 2003, 2006d).

Inconsistent with data reported elsewhere (Fawcett et al 1990), neither a history of previous suicide attempts nor psychic anxiety was able to predict suicide risk in our sample of MAD patients. On the contrary, we found that the somatic symptomatology of anxiety predicts suicide risk.

Lastly, pharmacotherapy was a strong predictor of suicide risk. It was the strongest predictor of suicide risk even after controlling for diagnosis, anxiety and depression severity, and sociodemographic variables. Mood stabilizer use as whole (considering both lithium and anticonvulsants) was the only protective factor for suicide risk in our analysis, but only before controlling for clinical and sociodemographic variables. This latter result could be explained by our inclusion of both lithium and anticonvulsants as mood stabilizers.

The predictive power of antidepressant use is relevant to the ongoing debate about the potential increase in suicidal risk among patients being treated with antidepressant drugs (FDA 2004; Baldessarini et al 2006c, 2006b; Simon et al 2006; Sondergard et al 2006). Several studies have failed to produce evidence of a significant effect of antidepressants on suicide risk (Simon et al 2006; Sondergard et al 2006).

In March 2004, the US FDA issued a public health advisory regarding worsening depression and suicidality in pediatric and adult patients being treated with several antidepressants (FDA 2004). Although, the question is still controversial (Simon et al 2006), Kahn and colleagues (Khan et al 2000) provided data on suicides and attempts extracted from controlled premarketing trials submitted to the FDA for several modern antidepressants, including SSRIs (paroxetine, sertraline) and other agents (mirtazapine, nefazodone), the older, standard drugs, and placebos. These pooled trials yielded relevant data for large numbers of subjects $(2,709-5,921)$, but for only brief exposures averaging 3-7 months. Minor differences were found in suicidal risk among the non-SSRI agents (3.46\%/year) and placebos (3.06\%/year), with a somewhat higher risk for
SSRIs (6.75\%/year). As suggested by Baldessarini collegues (2006b), suicidal ideation, but usually not suicidal behavior, can been reduced with antidepressant treatment. These considerations suggest that, suicidal acts require more than depressed mood and thoughts of death. The utility of the findings of the meta-analysis as a basis for sound clinical practice and regulatory policy is limited by the low levels of "suicidal events" reported, even lower frequency of actual suicidal behaviors, and variable outcomes across trials and treatments (Baldessarini et al 2006b).

Although the use of antidepressants seems not to be associated with an elevated suicide risk, there are circumstances when it is compulsory not to use antidepressants. Administration of antidepressants may lead to a switch from depression to mania or increase the irritable component of the disorder, a condition often associated with high suicide risk. In contrast, when high-voltage manic individuals slow down and their mood switches into depression, the reduced impetuousness and happiness can indicate an elevated suicide risk.

Impulsivity and aggression may be particularly important for both the risk and the timing of suicidal acts and may help to account for the striking disparity between the effectiveness of lithium in reducing suicidal risk and the lack of evidence of such an effect for antidepressants in the treatment of unipolar or bipolar major depression (Khan et al 2000, 2003; Jick et al 2004; Baldessarini 2005; Baldessarini et al 2005, 2006b; Baldessarini and Tarazi 2005; Gunnell et al 2005; Martinez et al 2005).

The role of mood-stabilizers appears to be the better remedy for the violent agitation that may precede suicide in bipolar disorders. Especially in mixed states, which may occur as a transitional condition when depression escalates into mania, the correct dosage of a mood stabilizer may determine whether or not an individual develops a high risk of suicide. Volatile and erratic moods associated with dysphoria and agitation should always lead clinicians to treat this condition carefully, monitoring suicide risk at all time. Antidepressants should be used only after careful assessment regarding the absence of such states (Rihmer and Akiskal 2006).

Psychiatric inpatients should always be followed-up soon after discharge as periods following hospitalization are often marked with high suicide risk, especially when patients face daily difficulties and cannot rely on family members or any social contact for support (Pompili et al 2005, 2006).

The present study had a number of limitations. The small sample size and the lack of information regarding long-term pharmacotherapy limit the generalization of the findings. 
Another limitation is that use of the BHS may have drawbacks which are shared by all self-administered psychometric instruments. Nevertheless, this simple, self-administered method has been reported as an important tool for the prediction of suicide (Beck et al 1989). The generalizability of our findings is limited by the usual difficulties of a retrospective assessment of suicide attempts and the review of clinical chart records. Furthermore, suicide attempts could not be classified retrospectively for their potential lethality. Finally, our patients had in some cases complex treatment regimens, including antidepressants administered alone, in combination or as add-on therapy. It could be argued that suicidality in these patients was affected by the antidepressant treatment. However clear scientific evidence supporting this notion is still lacking. One major point for further investigation is to take into consideration past pharmachological treatment including time and dosage.

In conclusion, we stress the need to better screen MAD patients for aggressiveness and impulsivity as well as suicide intent. The use of proper pharmacological therapy (especially lithium) can dramatically decrease deaths from suicide.

\section{References}

Anonymous. 1998. Atypical antipsychotics for treatment of depression in schizophrenia and affective disorders. Collaborative Working Group on Clinical Trial Evaluations. J Clin Psychiatry, 59(Suppl 12):41-5.

Ahrens B, Muller-Oerlinghausen B. 2001. Does lithium exert an independent antisuicidal effect? Pharmacopsychiatry, 34:132-6.

Baca-Garcia E, Oquendo MA, Saiz-Ruiz J, et al. 2006. A pilot study on differences in aggression in New York City and Madrid, Spain, and their possible impact on suicidal behavior. J Clin Psychiatry, 67:375-80.

Baldessarini RJ. 2005. Drug therapy of depression and anxiety disorders. In: Brunton LL, Lazo JS, Parker KL (eds). Goodman and Gilman's The Pharmacological Basis of Therapeutics. 11th ed. New York: McGrawHill Pr. pp. 429-59.

Baldessarini RJ, Pompili M, Tondo L. 2006a. Bipolar Disorder. In: Simon RI, Hales RE (eds). American Psychiatric Textbook of Suicide Assessment and Management. Washington, DC: American Psychiatric Publishing. pp. 277-99.

Baldessarini RJ, Pompili M, Tondo L. 2006b. Suicidal risk in antidepressant drug trials. Arch Gen Psychiatry, 63:246-8.

Baldessarini RJ, Pompili M, Tondo L. 2006c. Suicide in bipolar disorder: Risks and management. CNS Spectr, 11:465-71.

Baldessarini RJ, Pompili M, Tondo L, et al. 2005. Antidepressants and suicidal behavior: Are we hurting or helping? Clin Neuropsychiatry, 2:73-5.

Baldessarini RJ, Tarazi FI. 2005. Pharmacotherapy of psychosis and mania. In: Brunton LL, Lazo JS, Parker KL (eds). Goodman and Gilman's The Pharmacological Basis of Therapeutics. 11th ed. New York: McGrawHill Pr. pp. 461-500.

Baldessarini RJ, Tondo L, Davis P, et al. 2006d. Decreased risk of suicides and attempts during long-term lithium treatment: A meta-analytic review. Bipolar Disord, 8:625-39.

Baldessarini RJ, Tondo L, Hennen J. 2003. Lithium treatment and suicide risk in major affective disorders: Update and new findings. $J$ Clin Psychiatry, 64(Suppl 5):44-52.

Bauer MS, Mitchner L. 2004. What is a "mood stabilizer"? An evidencebased response. Am J Psychiatry, 161:3-18.
Beck AT, Brown G, Berchick RJ, et al. 1990. Relationship between hopelessness and ultimate suicide: A replication with psychiatric outpatients. Am J Psychiatry, 147:190-5.

Beck AT, Brown G, Steer RA. 1989. Prediction of eventual suicide in psychiatric inpatients by clinical ratings of hopelessness. $J$ Consult Clin Psychol, 57:309-10.

Beck AT, Steer RA, Kovacs M, et al. 1985. Hopelessness and eventual suicide: A 10-year prospective study of patients hospitalized with suicidal ideation. Am J Psychiatry, 142:559-63.

Bedrosian RC, Beck AT. 1979. Cognitive aspects of suicidal behavior. Suicide Life Threat Behav, 9:87-96.

Bongar B. 2000. The suicidal patient. In: Kazdin AE (ed). Encyclopedia of Psychology. Washington, DC: American Psychological Association, pp

Brodersen A, Licht RW, Vestergaard P, et al. 2000. Sixteen-year mortality in patients with affective disorder commenced on lithium. $\mathrm{Br} J$ Psychiatry, 176:429-33.

Buss AH, Perry M. 1992. The aggression questionnaire. JPers Soc Psychol, 63:452-9.

Chandrasekaran R, Gnanaselane J. 2005. Correlates of suicidal intent in attempted suicide. Hong Kong J Psychiatry, 15:118-21.

Chen YW, Dilsaver SC. 1996. Lifetime rates of suicide attempts among subjects with bipolar and unipolar disorders relative to subjects with other Axis I disorders. Biol Psychiatry, 39:896-9.

Coryell W, Young EA. 2005. Clinical predictors of suicide in primary major depressive disorder. J Clin Psychiatry, 66:412-17.

Dumais A, Lesage AD, Alda M, et al. 2005. Risk factors for suicide completion in major depression: a case-control study of impulsive and aggressive behaviors in men. Am J Psychiatry, 162:2116-24.

Fawcett J. 2007. Acute risk factors for suicide: Anxiety severity as a treatment modifiable risk factor. In: Tatarelli R, Pompili M, Girardi $\mathrm{P}$ (eds). Suicide in psychiatric disorders. New York: Nova Science Publishers, pp. 49-56.

Fawcett J, Scheftner WA, Fogg L, et al. 1990. Time-related predictors of suicide in major affective disorder. Am J Psychiatry, 147:1189-94.

Fossati A, Di Ceglie A, Acquarini E, et al. 2001. Psychometric properties of an Italian version of the Barratt Impulsiveness Scale-11 (BIS-11) in non clinical subjects. J Clin Psychol, 57:815-28.

Galfalvy H, Oquendo MA, Carballo JJ, et al. 2006. Clinical predictors of suicidal acts after major depression in bipolar disorder: A prospective study. Bipolar Disord, 8:586-95.

Goodwin FK, Fireman B, Simon GE, et al. 2003. Suicide risk in bipolar disorder during treatment with lithium and divalproex. JAMA, 290:1467-73.

Goodwin FK, Jamison KR 1990. Manic-depressive illness. New York: Oxford Univ Pr.

Grunze H, Kasper S, Goodwin G, et al. 2002. World Federation of Societies of Biological Psychiatry (WFSBP) Guidelines for Biological Treatment of Bipolar Disorders, Part I: Treatment of Bipolar Depression. World J Biol Psychiatry, 3:115-24.

Gunnell D, Saperia J, Ashby D. 2005. Selective serotonin reuptake inhibitors (SSRIs) and suicide in adults: Meta-analysis of drug company data from placebo controlled, randomised controlled trials submitted to the MHRA's safety review. BMJ, 330:385.

Guzzetta F, Tondo L, Centorrino F, et al. 2007. Lithium treatment reduces suicide risk in recurrent major depressive disorder. J Clin Psychiatry, 68:380-3.

Hamilton M. 1959. The assessment of anxiety states by rating. $\mathrm{Br} J \mathrm{Med}$ Psychol, 32:50-5.

Hamilton M. 1960. A rating scale for depression. J Neurol Neurosurg Psychiatry, 23:56-62.

Hamilton M. 1967. Development of a rating scale for primary depressive illness. Br J Soc Clin Psychol, 6:278-96.

Harris EC, Barraclough B. 1997. Suicide as an outcome for mental disorders. A meta-analysis. Br J Psychiatry, 170:205-28.

Hawton K, Sutton L, Haw C, et al. 2005. Suicide and attempted suicide in bipolar disorder: A systematic review of risk factors. J Clin Psychiatry, 66:693-704. 
Hendin H. 1986. Suicide: A review of new directions in research. Hosp Community Psychiatry, 37:148-54.

Inskip HM, Harris EC, Barraclough B. 1998. Lifetime risk of suicide for affective disorder, alcoholism and schizophrenia. $\mathrm{Br} J$ Psychiatry, 172:35-7.

Jick H, Kaye JA, Jick SS. 2004. Antidepressants and the risk of suicidal behaviors. JAMA, 292:338-43.

Kessler RC, Borges G, Walters EE. 1999. Prevalence of and risk factors for lifetime suicide attempts in the National Comorbidity Survey. Arch Gen Psychiatry, 56:617-26.

Khan A, Khan S, Kolts R, et al. 2003. Suicide rates in clinical trials of SSRIs, other antidepressants, and placebo: Analysis of FDA reports. Am J Psychiatry, 160:790-2.

Khan A, Warner HA, Brown WA. 2000. Symptom reduction and suicide risk in patients treated with placebo in antidepressant clinical trials: an analysis of the Food and Drug Administration database. Arch Gen Psychiatry, 57:311-7.

Lester D. 1993. Suicidal behavior in bipolar and unipolar affective disorders: A meta-analysis. J Affect Disord, 27:117-21.

Mann JJ, Waternaux C, Haas GL, et al. 1999. Toward a clinical model of suicidal behavior in psychiatric patients. Am J Psychiatry, 156:181-9.

Martinez C, Rietbrock S, Wise L, et al. 2005. Antidepressant treatment and the risk of fatal and non-fatal self harm in first episode depression: Nested case-control study. BMJ, 330:1-7.

Patton JH, Stanford MS, Barratt ES. 1995. Factor structure of the Barratt impulsiveness scale. J Clin Psychol, 51:768-74.

Pompili M, Mancinelli I, Ruberto A, et al. 2005. Where schizophrenic patients commit suicide: A review of suicide among inpatients and former inpatients. Int J Psychiatry Med, 35:171-90.

Pompili M, Tondo L, Grispini A, et al. 2006. Suicide attempts in bipolar disorder. Clin Neuropsychiatry, 3:327-31.

Potash JB, Kane HS, Chiu YF, et al. 2000. Attempted suicide and alcoholism in bipolar disorder: Clinical and familial relationships. Am J Psychiatry, 157:2048-50.

Rihmer Z. 2007. Suicide risk in mood disorders. Curr Opin Psychiatry, 20:17-22.

Schneider B, Muller MJ, Philipp M. 2001. Mortality in affective disorders. $J$ Affect Disord, 65:263-74.
Sheehan DV, Lecrubier Y, Sheehan KH, et al. 1998. The Mini-International Neuropsychiatric Interview (M.I.N.I.): the development and validation of a structured diagnostic psychiatric interview for DSM-IV and ICD10. J Clin Psychiatry, 59(Suppl 20):22-33; quiz 4-57.

Simon GE, Savarino J, Operskalski B, et al. 2006. Suicide risk during antidepressant treatment. Am J Psychiatry, 163:41-7.

Sondergard L, Kvist K, Andersen PK, et al. 2006. Do antidepressants precipitate youth suicide? A nationwide pharmacoepidemiological study. Eur Child Adolesc Psychiatry, 15:232-40.

Stelmachers ZT. 1995. Assessing suicidal clients. In: Butcher JN (ed). Clinical personality assessment. New York: Oxford University Pr. pp. 367-79.

Szadoczky E, Vitrai J, Rihmer Z, et al. 2000. Suicide attempts in the Hungarian adult population. Their relation with DIS/DSM-III-R affective and anxiety disorders. Eur Psychiatry, 15:343-7.

Thies Flechtner K, Muller Oerlinghausen B, Seibert W, et al. 1996. Effect of prophylactic treatment on suicide risk in patients with major affective disorders: Data from a randomized prospective trial. Pharmacopsychiatry, 29:103-7.

Tiihonen J, Lonnqvist J, Wahlbeck K, et al. 2006. Antidepressants and the risk of suicide, attempted suicide, and overall mortality in a nationwide cohort. Arch Gen Psychiatry, 63:1358-67.

Tondo L, Baldessarini RJ, Floris G. 2001. Long-term clinical effectiveness of lithium maintenance treatment in types I and II bipolar disorders. $\mathrm{Br}$ J Psychiatry Suppl, 178:S184-90.

Tondo L, Isacsson G, Baldessarini R. 2003. Suicidal behaviour in bipolar disorder: Risk and prevention. CNS Drugs, 17:491-511.

US Food and Drug Administration. 2004. FDA public health advisory: Worsening depression and suicidality in patients being treated with antidepressant medications. CfDEaR. March 22, 2004.

US Public Health Service. 1999. The Surgeon General's Call To Action To Prevent Suicide. Washington, DC.

Weissman M, Fox K, Klerman GL. 1973. Hostility and depression associated with suicide attempts. Am J Psychiatry, 130:450-5.

Weissman MM, Bland RC, Canino GJ, et al. 1999. Prevalence of suicide ideation and suicide attempts in nine countries. Psychol Med, 29:9-17.

Wetzel RD, Margulies T, Davis R, et al. 1980. Hopelessness, depression, and suicide intent. J Clin Psychiatry, 41:159-60. 
